\title{
Estágio com Pesquisa na Formação Inicial de Professores: transformação dos sentidos sobre a atividade docente
}

\section{Internship and Research in Initial Teacher Education: changes in personal meanings of the teaching activity}

(iD)

Leandro de Oliveira Rabelo ${ }^{1}$

Maria Lucia Vital dos Santos Abib ${ }^{2}$

Maria Nizete de Azevedo ${ }^{3}$

'Universidade de São Paulo (USP), Programa de Pós-Graduação Interunidades em Ensino de Ciências, São Paulo, SP, Brasil. Autor Correspondente: leandrorabelo@usp.br

${ }^{2}$ Universidade de São Paulo (USP), Faculdade de Educação, Departamento de Metodologia do Ensino e Educação Comparada, São Paulo, SP, Brasil.

${ }^{3}$ Universidade Federal de São Paulo (UNIFESP), Diadema, SP, Brasil.

Resumo:Com base naTeoria Histórico-Cultural da Atividade, analisamos as transformações dos sentidos de um licenciando em atividade de estágio supervisionado com pesquisa, sobre a atividade docente, em especial a aprendizagem dos alunos e a experimentação no Ensino de Física. Esse estágio, que visa articular teoria-prática na formação inicial de professores, foi realizado no contexto das disciplinas de Metodologia do Ensino de Física, oferecidas por uma universidade pública brasileira. Utilizamos dados do relatório de estágio e de uma entrevista semiestruturada. Os resultados indicam que, inicialmente, o estágio não se caracterizava como uma atividade para esse sujeito, mas apenas uma ação necessária à conclusão da graduação, e seus sentidos se aproximavam de um ensino-aprendizagem transmissivo/receptivo. Contudo, no decorrer do processo formativo, foram elaborados novos sentidos sobre a atividade docente. Esses resultados reforçam a importância da pesquisa na realização do estágio supervisionado na formação inicial de professores.

Palavras-chave: Ensino de física; Formação inicial de professores; Estágio supervisionado; Relação teoria-prática.

Abstract: Based on Cultural-historical Activity Theory, we analyze the transformations of a future teacher's personal meanings of teaching during supervised internship and research, especially student learning and experimentation in Physics Teaching. This internship aimed to articulate theory and practice in initial teacher education and was carried out as part of courses in Methodology of Physics Teaching offered by a Brazilian public university. We used data from the supervised internship report and a semi-structured interview. The results indicate that, initially, the supervised internship was not characterized as an activity for the future teacher, but only as an action needed to complete the undergraduate degree. His personal meanings of the teaching activity neared the notion of teaching-learning transmissive/receptive. However, during the formative process, new personal meanings of the teaching activity were elaborated. These results reinforce the importance of the supervised internship, together with research, in initial teacher education.

Keywords: Physics teaching; Initial teacher education; Supervised internship; Theorypractice relationship.

Recebido em: 22/11/2019

Aprovado em: 20/08/2020 


\section{Introdução}

$\mathrm{Na}$ formação inicial de professores, os licenciandos, ao iniciarem o ensino superior, já têm diversos sentidos sobre a atividade docente, constituídos durante a vida escolar. Ou seja, como passaram muitos anos na escola, antes mesmo da formação inicial, já desenvolveram diversos sentidos sobre o ensino e a aprendizagem, o papel do professor e da escola, a aprendizagem dos alunos, entre outros.

Tardif e Raymond (2000) afirmam que a forma de entender a atividade docente elaborada no decorrer da vida escolar é muito forte e, muitos licenciandos passam pelos cursos de formação inicial de professores sem alterarem de forma significativa suas concepções sobre o que é ser professor e seu papel em relação à aprendizagem dos alunos. Caso o conteúdo desses sentidos não seja alterado, esses sujeitos, ao iniciarem a carreira, podem tomar como referência o modo de agir de seus antigos professores e dos contextos escolares dos quais fazem parte, podendo incorporar de modo acrítico rotinas e modos de ensinar pouco promissores para a aprendizagem dos estudantes que se aproximavam de um ensino-aprendizagem transmissivo/receptivo.

Para que isso não ocorra, de modo a propiciar a transformação dos sentidos sobre a atividade docente dos futuros professores, supomos ser importante mobilizar os licenciados em atividades que articulem teoria e prática na formação inicial. Tal articulação é defendida por muitos autores (BASTOS; NARDI, 2018; GIROUX, 1997; LIBANÊO, 2018; PIMENTA; LIMA, 2017; SAVIANI, 2009; ZEICHNER; DINIZ-PEREIRA, 2005), a considerarem os limites da formação que privilegia um dos polos (teórico ou prático) por não criar possibilidades de articular a concepção e a execução no âmbito dos atos de planejar, desenvolver e refletir, inerentes à docência em sua complexidade. Tal como afirmam Lima e Pimenta (2006), uma forma de articular teoria e prática na formação inicial de professor é realizar estágios supervisionados com pesquisa. Nesses estágios, os licenciandos desenvolvem "[...] postura e habilidades de pesquisador a partir das situações de estágio, elaborando projetos que lhes permitam ao mesmo tempo compreender e problematizar as situações que observam" (LIMA; PIMENTA, 2006, p. 14).

Nessa perspectiva, com base na Teoria Histórico-Cultural da Atividade (ENGESTRÖM, 2001; LEONTIEV, 2010), analisamos uma proposta de organização do estágio supervisionado que busca articular teoria e prática na formação inicial de professores, por meio do desenvolvimento de projetos de investigação sobre a docência, denominados Projeto de Investigação em Docência (PID). Essa proposta de estágio supervisionado tem sido realizada em disciplinas de Metodologia do Ensino de Física (MEF), oferecidas aos alunos de Licenciatura em Física por uma universidade pública do Estado de São Paulo. De modo mais específico, analisamos as transformações, ocorridas ao longo do processo formativo, dos sentidos atribuídos por ele ao estágio supervisionado e à atividade docente, com ênfase em dois aspectos, em especial a aprendizagem dos alunos e a experimentação no Ensino de Física (EF).

\section{Teoria Histórico-Cultural da Atividade}

A Teoria da Atividade teve seu surgimento na psicologia histórico-cultural desenvolvida no contexto pós-revolucionário soviético por L. S. Vigotski (1896-1934), A. N. Leontiev (1903-1979), A. R. Luria (1902-1977) e outros psicólogos russos. 
Para Leontiev (2010), a consciência do indivíduo se desenvolve quando ele é mobilizado a buscar modos para satisfazer necessidades, oriundas da sua relação com o meio social e cultural. O autor define atividade como "[...] os processos psicologicamente caracterizados por aquilo a que o processo, como um todo, se dirige (seu objeto), coincidindo sempre com o objetivo que estimula o sujeito a executar esta atividade, isto é, o motivo" (LEONTIEV, 2010, p. 68). Assim, para esse autor, a "[...] principal coisa que distingue uma atividade de outra reside na diferença entre os seus objetos" (LEONTIEV, 1980 , p. 55), sendo o motivo o que impulsiona o sujeito a realizar a atividade.

As componentes da atividade são as ações que correspondem "[...] à noção de resultado que deve ser alcançado, isto é, o processo que obedece a um fim consciente" (LEONTIEV, 1980, p. 55), sendo que uma mesma ação pode ser utilizada em diferentes atividades. Contudo, destacamos o caráter coletivo da atividade, com número ilimitado de ações, cujas finalidades específicas são necessariamente correlacionadas ao objeto da atividade da qual fazem parte. Tais ações são realizadas por meio de operações que dependem das condições objetivas para realizá-las. Essas categorias que definem a atividade humana são dinâmicas, podendo ser alteradas e transformadas constantemente.

A atividade pode perder o motivo que a provocou, e nesse caso transformar-se numa ação que realiza uma relação com o mundo provavelmente muito diferente; reciprocamente, a ação pode adquirir uma força motivante independente e tornarse uma variedade especial de atividade, e finalmente a ação pode ser transformada num meio de alcançar um fim capaz de realizar diferentes ações. (LEONTIEV, 1980, p. 57).

É o que ocorre no processo de desenvolvimento histórico-cultural. O ser humano, ao criar diversos objetos para a satisfação de seus desejos, gerou novas necessidades, tornando a atividade humana mais complexa, composta de ações individuais dentro de uma divisão de trabalho (LEONTIEV, 2010). Nesse processo, a linguagem e as relações sociais têm papel fundamental, pois permitem que o ser humano transmita sua herança cultural às novas gerações. Entretanto, tal como nos alerta Leontiev (2004), a transformação da consciência social para consciência individual não acontece de maneira passiva e direta.

Para esse autor, ao iniciar a vida "[...] o homem encontra um sistema de significações pronto, elaborado historicamente, e apropria-se dele tal como se apropria de um instrumento, esse precursor material da significação" (LEONTIEV, 2004, p. 102). Porém, a forma como cada indivíduo assimila ou se apropria de determinada significação históricosocial, depende dos sentidos que atribui a tais significações.

Assim, o autor define dois conceitos fundamentais naTeoria da Atividade: significado e sentido. Para Leontiev (2004), os significados estão relacionados com as significações histórico-sociais que permitem a generalização da realidade, sendo estabelecidos pela linguagem, portanto, como conteúdo da consciência social. Os sentidos devem ser entendidos na sua relação com a vida e a atividade do sujeito, ou seja, desencadeados por seus motivos, de modo que revelam a relação pessoal e subjetiva do indivíduo com os fenômenos e objetos. Portanto, o ser humano, em seus processos interativos com o contexto sociocultural, pode, em função de novas necessidades surgidas em tais interações, vir a alterar seus motivos, modificando também seus sentidos e sua atividade. Assim, estabelecendo novas relações com o mundo e os outros seres humanos, modifica também sua consciência. 
Nessa compreensão, há uma relação entre motivo, sentido e atividade. Somente há atividade quando "[...] objetivo e motivo são coincidentes, assim como significação e sentido são correspondentes" (AZEVEDO, 2013, p. 41). Para o homem primitivo, sentidos e significados eram coincidentes, o individual e o social pouco se diferenciavam. Todavia, com a divisão social do trabalho e o advento da propriedade privada inerentes à sociedade capitalista, houve a dissociação entre a significação social do trabalho e o sentido que Ihe é atribuído pelo sujeito. Assim, os sentidos e os significados deixaram de ser coincidentes, acarretando em um processo de alienação da atividade humana que se caracteriza pela "[...] discordância entre o resultado objetivo da atividade humana e o seu motivo (LEONTIEV, 2004, p. 130)", convertendo-se na perda do domínio, pelo trabalhador, sobre a totalidade de seu trabalho.

Para o trabalhador alienado, tanto o motivo, como o sentido que atribui ao seu trabalho não são coincidentes com o objetivo e com a significação social da atividade. No caso da atividade docente, a alienação ocorre quando o professor realiza seu trabalho apenas para ganhar seu salário e garantir sua sobrevivência, sem considerar o significado social dessa atividade, isto é, como atividade mediadora entre o aluno e os instrumentos culturais. Essa alienação é intensificada pelas políticas neoliberais dirigidas à educação, as quais atrelam os objetivos educacionais às metas econômicas de produção e consumo, causando o esvaziamento do papel da escola no desenvolvimento integral do ser humano (LIBÂNEO, 2018). Esse quadro intensifica a proletarização do trabalho docente, pois diminui sua capacidade de reflexão sobre sua prática e sobre o que as políticas educacionais exigem, favorecendo "[...] a ruptura entre anseios subjetivos do sujeito professor e a função social de sua profissão" (AZEVEDO; ABIB; TESTONI, 2018, p. 323). Tal como preconiza Marx (1985), a ruptura promovida pelo trabalho alienado nega a atividade humana como práxis e, por conseguinte, obstaculiza o desenvolvimento humano em suas diferentes dimensões.

Para entender esse processo de alienação, Leontiev (1984) distingue dois tipos de motivos. Os motivos geradores de sentido (ou motivos eficazes) que "[...] ocupam um lugar hierárquico superior" (LEONTIEV, 1984, p. 158, tradução nossa), pois, na estrutura da atividade, outorgam um sentido pessoal à atividade, ou seja, o sujeito a realiza para suprir necessidades e desejos que Ihes são próprios; e os motivos-estímulos (ou motivos compreensíveis), externos ao sujeito, que cumprem apenas a função de estimulação complementar (positiva ou negativa) da atividade. Esses dois tipos de motivos são importantes para que se compreenda a mobilização dos sentidos do sujeito em uma atividade. Para Leontiev (1984), o sujeito está em atividade quando seu motivo coincide com o objetivo da atividade, na qual ele está inserido. Nesse caso, estamos nos referindo ao motivo gerador de sentido.

Para esclarecer, vamos exemplificar. Caso estejamos nos referindo a um licenciando, por exemplo, o motivo que o impele a agir seria, digamos, o de se formar professor e se iniciar na docência, logo que possível, como tal, gerador de sentido, uma vez que coincide com o objetivo do curso de licenciatura, o de proporcionar a formação de professores mobilizados a garantir a aprendizagem de seus futuros estudantes. Esse estudante de licenciatura, portanto, estaria inserido no plano da construção do seu processo formativo e, por suposto, de sua futura docência como atividade humana ou práxis.

Para estudar o desenvolvimento e as transformações da atividade humana, em especial a formação para a futura docência, é preciso analisar os motivos que mobilizam os sujeitos e a relação entre as significações sociais e os sentidos que eles atribuem à 
atividade que realizam. Para isso, é necessário um instrumento que permita analisar tais relações. Esse instrumento teórico foi desenvolvido pelo finlandês Yrjö Engeström.

Com base nessas ideias de Leontiev (1984, 2004, 2010), Engeström (1987) ampliou a Teoria da Atividade, elaborando um modelo teórico que engloba as relações complexas das redes de atividades, com foco na inter-relação entre os sujeitos em uma comunidade e avançando no entendimento dos processos de transformação dos sistemas de atividade. Esse modelo teórico de uma atividade pode ser representado pela Figura 1.

Sem perder de vista a unidade dialética da atividade humana, o triângulo superior (Sujeito/Objeto/Ferramentas e Signos) na Figura 1 pode ser visto como a ponta do iceberg que representa "[...] as ações individuais e grupais alinhadas em um sistema de atividade coletiva" (ENGESTRÖM, 2001, p. 134, tradução nossa). A base do triângulo (Regras/Comunidade/Divisão do Trabalho) é composta pelos elementos do ambiente social no qual a atividade ocorre nas suas multiplicidades de relações, que podem ser analisadas por meio das tríades de mediação. O círculo oval indica que "[...] as ações orientadas para o objeto são sempre, explícita ou implicitamente, caracterizadas por ambiguidade, surpresa, interpretação, busca de sentido e potencial para mudanças" (ENGESTÖM, 2001, p. 13, tradução nossa).

Figura 1 - Modelo da estrutura da atividade humana

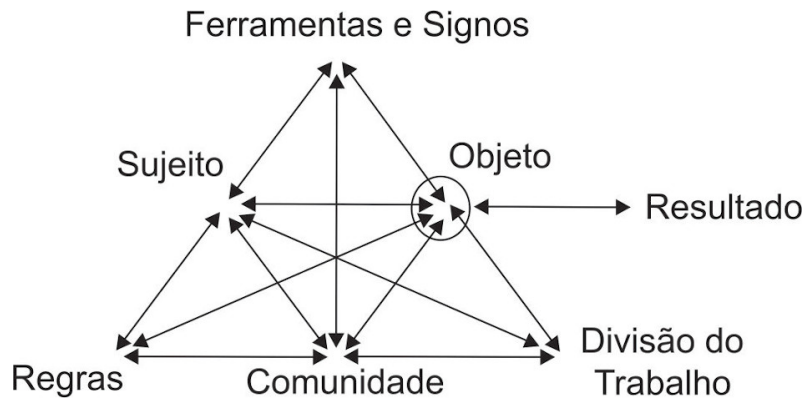

Fonte: adaptado de Engeström (2001, p. 135).

Tal representação se refere a um sistema de atividade, contudo, na vida cotidiana, diversos sistemas de atividade se relacionam, influenciando uns aos outros. Dessas relações, e no interior de cada sistema de atividade, podem surgir tensões, dilemas e conflitos entre os diferentes sujeitos e elementos dos sistemas de atividades, podendo levar à transformação desses próprios sistemas. Esses fatores que impulsionam as mudanças nos sistemas de atividade são chamados contradições (ENGESTRÖM, 1987).

Esse conceito deve ser entendido em sua concepção dialética, isto é, existem elementos opostos em uma relação histórica e social que evoluem com o tempo. As contradições são tensões históricas em evolução, forças motrizes de transformação "[...] que tornam o objeto um alvo em movimento, motivador e gerador do futuro" (ENGESTRÖM, 1987, p. 5, tradução nossa). Em tais condições, as contradições podem levar o sujeito a desenvolver novos motivos, transformando ou impulsionando sua atividade, ao possibilitar novos sentidos (motivos geradores de sentido) e/ou estimulá-la (motivos-estímulos).

As contradições podem ser divididas em quatro níveis, conforme a Figura 2. 
Figura 2 - Níveis de contradições

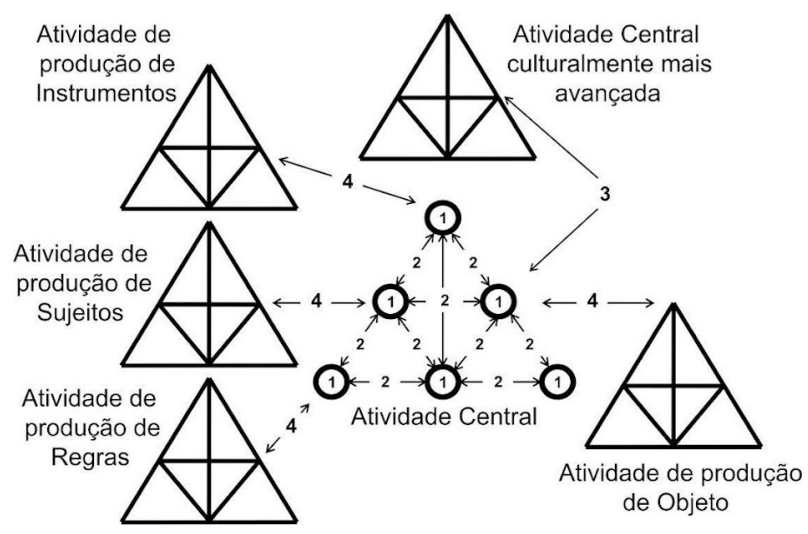

Fonte: adaptado de Engeström (1987).

A contradição primária, a principal do sistema capitalista, surge do conflito interno entre valor de troca e valor de uso, estando presente em cada um dos elementos do triângulo do sistema de atividade central (aquela focalizada na investigação). A contradição secundária tem origem na relação entre cada um dos elementos que compõe o sistema de atividade central. A contradição terciária aparece quando uma atividade dominante, representante de uma cultura mais avançada, introduz um objeto ou um motivo novo na atividade central, podendo provocar resistência dos sujeitos envolvidos na atividade central. Para exemplificar essa contradição, Engeström (1987) utiliza o exemplo da escola, onde os professores buscam fazer as crianças estudarem, enquanto elas querem apenas brincar com seus colegas. A contradição quaternária surge quando há a influência de atividades vizinhas (atividades essenciais à atividade central), produzindo novos instrumentos (ferramentas e signos), sujeitos (instrução e educação escolar dos sujeitos da atividade), regras ou objetos para a atividade central.

Em nossa pesquisa, como analisamos o estágio supervisionado como atividade central, podemos considerar sistemas de atividades vizinhas aquelas produzidas no âmbito da escola e da universidade. Nesse caso, esses sistemas de atividade não apenas influenciam a atividade central, mas a condicionam, pois o estágio supervisionado ocorre na relação entre esses dois sistemas de atividade.

\section{Contexto da Pesquisa}

Este artigo é um recorte de uma pesquisa mais ampla, realizada nas disciplinas de Metodologia de Ensino de Física I e II (MEF) de uma universidade estadual de São Paulo, as quais têm, na totalidade, 180 horas de carga horária de estágio supervisionado. Nessas disciplinas ocorreram aulas semanais com duração de três horas e trinta minutos com a abordagem de diversos temas, por meio de leituras e discussões coletivas de textos teóricos, sobre o ensino e aprendizagem, e sobre o Ensino de Física, tais como: teorias de aprendizagem, ensino por investigação, papel da experimentação, matemática no ensino de Física, o uso de histórias em quadrinhos, avaliação do ensino e da aprendizagem dos alunos, entre outros. Além disso, nas disciplinas, os alunos elaboraram portfólios reflexivos, nos quais apresentaram sínteses dos textos teóricos estudados, descreveram e analisaram as atividades realizadas no estágio supervisionado e nas aulas de MEF. Esses portfólios assumem o papel não 
só burocrático de avaliação na disciplina, mas também de instrumento de formação do licenciando, pois permitem o registro dos acontecimentos, bem como reflexões e (auto) análises do processo de desenvolvimento do estágio supervisionado.

Na MEF, o estágio supervisionado é organizado por meio da realização do Projeto de Investigação em Docência (PID) que visa integrar as articulações entre concepções pessoais, teorias acadêmicas e aspectos da prática docente no contexto escolar, por meio de atividades que congregam os procedimentos de ensino postos em curso, e a pesquisa sobre eles, em uma perspectiva cujos futuros professores possam empreender reflexões compartilhadas e fundamentadas sobre suas próprias práticas ao longo do estágio. Tal proposta tem sido desenvolvida no âmbito de um grupo de pesquisa sobre a formação de professores por meio de um conjunto de investigações sobre a aprendizagem da docência no estágio supervisionado.

No processo de desenvolvimento do PID há diferentes etapas, com objetivos específicos. Essas etapas, representadas na Figura 3, não são lineares, pois, à medida que avançamos, é possível encontrar elementos das anteriores.

Tal esquema de representação do PID foi elaborado tendo como base a teoria da aprendizagem expansiva (ENGESTRÖM; SANNINO, 2010). A aprendizagem expansiva pode ser entendida como um processo em que os sujeitos, em um primeiro momento, questionam o sistema de atividades do qual fazem parte. Em seguida, analisam e propõem, coletivamente, novos modelos de atividade para superar as contradições que surgem no processo. Por fim, implementam e avaliam tais modelos, de modo a consolidar um novo sistema de atividades.

Figura 3 - Etapas do Projeto de Investigação em Docência (PID)

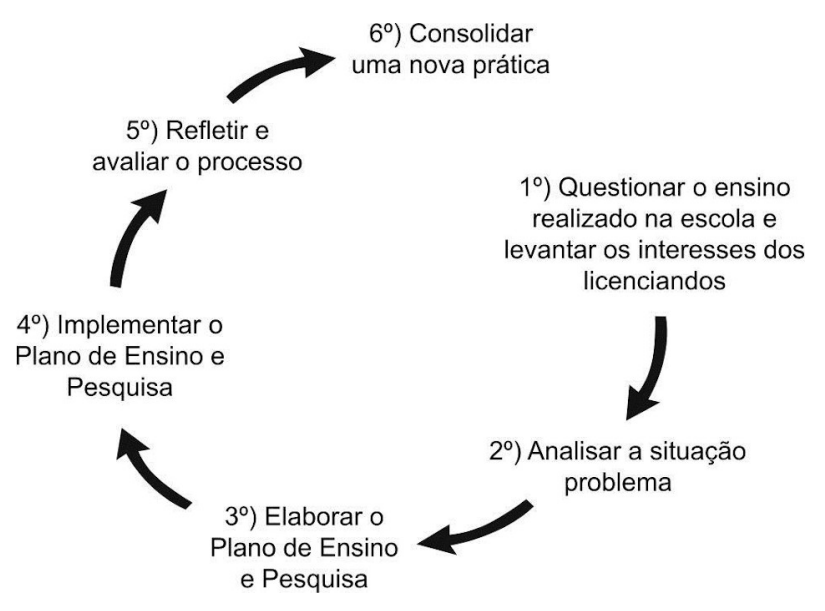

Fonte: elaborada pelos autores.

Conforme a Figura 3, no processo de realização do PID, inicialmente os interesses e expectativas dos licenciandos são levantados, por meio de questões para discussão e problematização das demandas, concepções e vivências anteriores dos alunos, como por exemplo: o que você gostaria que fosse respondido nessa disciplina?; para que é preciso estudar Física?; o que é ensinar?; o que é aprender? Concomitantemente, os futuros professores realizaram ações de questionamento sobre o ensino de Física praticado nas escolas de seus estágios, o qual, usualmente, ocorre de maneira transmissiva e passiva por parte do aluno. Isso, geralmente, ocorre por meio da observação e análise das aulas de Física das escolas de estágio, e entrevistas com egressos do ensino médio. Nessas 
entrevistas, as perguntas são relativas à importância do EF na formação de educação básica para suas vidas e seu trabalho.

Com o levantamento das necessidades e dos interesses dos licenciandos, o questionamento sobre o EF praticado nas escolas de estágio e as leituras teóricas (relativas ao papel e importância do EF em nossa sociedade), espera-se que os futuros professores se deparem com algumas das situações-problema relacionadas ao ensino praticado nessas escolas, muitas vezes, livresco e memorístico, de modo a mobilizá-los a buscar modos de ensinar alternativos aos observados. Ao analisarem essas situaçõesproblema, os estagiários são incentivados a buscar soluções para os problemas encontrados nas escolas e a refletir sobre quais questões de ensino-pesquisa gostariam que fossem respondidas no desenvolvimento do PID.

Essas questões, cujo conteúdo expressam, em muitos casos, preocupações mais amplas sobre o ensino e a aprendizagem (qual o melhor método de ensino?, como motivar os alunos?, como lidar com a indisciplina dos alunos?, etc.), são discutidas coletivamente nas aulas de MEF, de modo a buscar focalizá-las, tendo em vista os contextos das escolas de estágio, as metodologias (ou instrumentos metodológicos) a serem utilizadas, e os conteúdos a serem tratados nas atividades de regência. Nesse processo, destaca-se a mediação da docente da disciplina na orientação dos licenciandos na transformação de suas inquietações e curiosidades, em perguntas com teor epistemológico e caráter investigativo. Desse movimento, resulta um problema de ensino/pesquisa.

A partir disso, os licenciandos elaboram um plano de ensino articulado a um plano de investigação, buscando definir as estratégias para solucionar e/ou responder o problema de ensino/pesquisa. Esses planos são apresentados e discutidos nas aulas da disciplina, a fim de incorporar as sugestões, possibilitando uma consistência entre os objetivos do projeto e seus modos de ação. Posteriormente, os licenciandos, em seu campo de estágio e com apoio do professor que supervisiona o estágio na escola, realizam as atividades de regências planejadas na universidade sob a mediação da professora orientadora (docente da disciplina). Simultaneamente, registram as regências, por meio de gravações de áudio e de vídeo, notas de campo, e trabalhos escritos realizados pelos alunos para obterem informações que subsidiem as análises necessárias, conforme o plano de pesquisa.

Por fim, nas etapas finais, o processo desenvolvido na universidade e na escola é analisado pelos estagiários com o intuito de refletir sobre os problemas de ensino e pesquisa formulados e as situações vivenciadas no contexto escolar. Para potencializar e sistematizar essas reflexões, eles apresentam suas análises realizadas no PID nas últimas aulas de MEF. Com apoio dos colegas e da docente responsável, buscam ampliar e aprofundar as análises realizadas, de modo a compartilhar e consolidar novas práticas.

\section{Metodologia de Pesquisa}

Nesta pesquisa, investigamos um caso particular, a considerar que o singular se legitima como fonte de produção teórica, "[...] entendendo por teórica a construção permanente de modelos de inteligibilidade que Ihe deem consistência a um campo ou um problema na construção do conhecimento" (GONZÁLEZ-REY, 2015, p. 11). Utilizamos o método de análise por unidades de Vigotski (2010), que se propõe a realizar 
[...] uma análise do processo em oposição a uma análise do objeto; uma análise que revela as relações dinâmicas ou causais, reais, em oposição à enumeração das características externas de um processo, isto é, uma análise; explicativa e não descritiva; e uma análise do desenvolvimento que reconstrói todos os pontos e faz retornar à origem o desenvolvimento de uma determinada estrutura. (VIGOTSKI, 2010, p. 69).

Para isso, selecionamos como unidade de análise o sistema de atividade do estágio supervisionado, realizado por um licenciando em 2017, na disciplina de MEF. O sujeito foi selecionado durante o processo de observação participante, proporcionado por um dos autores deste artigo nas aulas da disciplina Metodologia do Ensino de Física II e pela análise prévia dos portfólios entregues ao final dessa disciplina. O critério da escolha do sujeito foi a qualidade das informações necessárias à pesquisa, isto é, a clareza, a amplitude e a profundidade das informações fornecidas pelo licenciando.

Para construir as informações necessárias à pesquisa, utilizamos os textos presentes no portfólio entregue por esse sujeito: resenhas de textos teóricos, planejamento do PID, relatórios de observação e regência, conclusões do estágio. Tais textos foram lidos na íntegra, de modo a selecionar e organizar as informações relevantes à pesquisa. Em seguida, com base nessas informações, elaboramos um roteiro de entrevista semiestruturada, aplicada ao sujeito. Para essa entrevista, apoiamo-nos em um roteiro com perguntas abertas para orientar a conversa e composto pelos seguintes tópicos: (i) escolha profissional e perspectivas futuras; (ii) formação inicial; (iii) estágio supervisionado; (iv) Metodologia do Ensino de Física; e (v) desenvolvimento do PID.

Para analisar as transformações dos sentidos e motivos do sujeito no processo de realização do estágio supervisionado, focalizamos nas contradições que emergiram durante o processo formativo, buscando indícios de como elas favoreceram mudanças em seu sistema de atividades.

\section{Análise dos Resultados}

O sujeito da pesquisa, ao concluir a educação básica, iniciou o ensino superior em um curso de engenharia e começou a trabalhar como plantonista no curso pré-vestibular da escola em que estudou no ensino médio. Inicialmente, embora tenha exercido esse trabalho, ele não tinha como meta ser professor. Porém, com o tempo, passou a gostar dessa atividade de tirar dúvidas dos alunos e decidiu fazer o curso de bacharelado em Física. Entretanto, apesar dessa mudança de curso, ele ainda não tinha certeza de sua escolha profissional. É o que ele nos diz em sua entrevista:

Inicialmente, não era algo que eu encarava como uma possível profissão. Eu só gostava de resolver os exercícios. [...] Talvez, além de achar legal responder as perguntas e resolver aquelas questões, tinha um pouco de fetiche, um pouco da questão da autoridade, o cara que sabe. [Entrevista].

Depois de dois anos e meio, ele decidiu mudar para o curso licenciatura em Física. Um ano depois dessa transferência de curso, frequentou as disciplinas de MEF, tendo realizado poucas disciplinas de ensino e educação. Inicialmente, seus sentidos sobre a atividade docente e aprendizagem dos alunos eram limitados às experiências que teve como aluno de educação básica, nas disciplinas do curso de bacharelado em Física e como monitor no curso pré-vestibular que atuava. Como ele próprio disse: 
"Eu nunca tinha vivenciado uma estrutura de aula da faculdade de educação. Pra mim aula era lousa, teorema, demonstração e exemplo" [Entrevista].

Além disso, seus sentidos em relação ao curso de licenciatura e, portanto, com a atividade de estágio supervisionado, estavam relacionados à obtenção da certificação que Ihe faltava para se tornar professor na escola que atuava como plantonista. Esses sentidos conferiam apenas um motivo-estímulo para realizar o estágio supervisionado. Um exemplo disso é que, quando foi questionado sobre as escolhas metodológicas de ensino a serem utilizadas no PID, ele afirmou que escolheu a experimentação no EF por julgar que Ihe daria o menor trabalho possível.

Uma motivação que talvez não se deva mencionar, mas sendo sincero, nós pensamos na questão da quantidade de trabalho que a gente iria ter. Para levar só a disciplina, com as discussões e os textos já é trabalhoso. Somado com a quantidade de estágio, era uma carga muito grande, tomava muito tempo. [Entrevista].

Nessa fala podemos perceber que há uma contradição primária em seu sistema de atividade, pois, apesar de o licenciando não ser pago para realizar o estágio supervisionado, a busca por diminuir o trabalho e tempo gasto na atividade têm relação direta com produção no sistema capitalista. Considerando Silva (2005), no sistema educativo, seja de nível básico ou superior, há uma relação análoga ao trabalho, na qual é possível trocar esforço por notas, aprovações, créditos necessários à certificação nos cursos. Desse modo, a realização do estágio supervisionado não se configurava uma atividade para esse sujeito, mas uma ação da sua atividade no curso Licenciatura em Física, cujo objetivo era a certificação como licenciado em Física com o menor esforço possível. Ou seja, ele estava afastado, melhor dito, alienado em relação ao objetivo da atividade de estágio supervisionado.

Apesar de estimulá-lo a realizar as ações necessárias para o estágio supervisionado, essa contradição possibilitou apenas motivos-estímulos para realizar as ações previstas no PID, indicando que há um afastamento entre os objetivos do sujeito e a significação social do estágio. Essa dissociação caracteriza um quadro de alienação, superável em um processo de construção de novos sentidos desencadeados por motivos, cujos conteúdos fossem coincidentes com os objetivos da atividade do estágio supervisionado. No caso em estudo, isso ocorreu no decorrer do processo de realização do estágio supervisionado, quando outras contradições surgiram com potenciais para gestão de novos motivos. Uma dessas contradições emergiu por uma demanda da escola:

Eu pensei na estrutura da escola. A escola [estágio] onde eu estava, eles receberam uma grande quantidade de equipamentos de laboratório. O coordenador comentou sobre isso. Eles tinham aula de laboratório, então ele comentou um problema: 'a gente tem esse monte de equipamento só que a gente não sabe usar'. [...] Tudo aquilo lá estava à disposição. Era uma demanda da escola, pois, mesmo depois de acabar o estágio, eu fui lá mais um ou dois dias para ir mexer nessas coisas lá. Eu pensei em usar esses materiais. [Entrevista].

Esse trecho evidencia que o sistema de atividade da escola produziu novos instrumentos para ele. Ou seja, houve uma contradição quaternária, pois o pedido do coordenador para que ajudasse a otimizar o uso dos equipamentos experimentais possibilitou novos instrumentos para a atividade central (estágio supervisionado). Isso favoreceu a produção de novos sentidos para a realização do estágio supervisionado 
do licenciando, os quais tinham conteúdos diferentes dos sentidos iniciais de diminuir o trabalho na disciplina, levando-o a assumir algumas demandas da escola além daquelas que precisava cumprir, aumentando o seu trabalho no estágio supervisionado.

Esses novos sentidos sobre a atividade de estágio, embora sejam desencadeados por motivos-estímulos, pois não coincidiam com os objetivos da atividade do estágio supervisionado da MEF, estimularam-no a realizar as ações necessárias ao estágio com maior dedicação, pois trouxeram novas responsabilidades para o licenciando.

Além desses novos sentidos, outros surgiram durante o processo de realização do PID. Isso pode ser percebido com o fato de, embora afirmar que almejava ter o menor trabalho possível na disciplina de MEF, o licenciando demonstrou, com o passar do tempo, um grande engajamento nas atividades realizadas. Ele realizou até mesmo ações além das exigidas, como o estudo de textos levantados na literatura da área de pesquisa em ensino de física.

Ao ser questionado na entrevista sobre o que o levou a recorrer a tais leituras extras, ele respondeu da seguinte maneira:

Então, primeiro a necessidade. A gente foi buscando os textos conforme a nossa necessidade. [...] A
gente foi vendo as referências dos trabalhos que já tinha. Foi indo pela nossa necessidade. [...] A gente
pegou alguns, foi tocando o estágio, aí a gente percebeu que os textos que estávamos trabalhando
talvez não fossem suficientes para nossa proposta. [...] Como a proposta do trabalho era bem aberta, a
gente também se sentiu bem livre para procurar coisas a mais. E também, acho que a [...] [professora da
disciplina] tinha deixado claro que você pode ir, na verdade, você vai ter que ir atrás, porque os textos que
vamos discutir aqui não vão ser suficientes para a peculiaridade de cada trabalho. [Entrevista].

Esse trecho nos revela duas contradições importantes que mobilizaram o sujeito a transformar seu sistema de atividade. A primeira contradição, a qual nos parece de nível terciário, surgiu da mediação da docente de MEF. Ela, ao propor que os estagiários realizassem o PID, ou seja, atividades de investigação nas escolas de educação básica, as quais exigiam criatividade e autonomia, introduziu um novo motivo, culturalmente mais avançado, aos sistemas de atividades dos licenciandos. Além de realizarem as regências de aulas na escola, comuns aos estágios supervisionados, os licenciandos também deveriam realizar investigações sobre essas regências. Dessa maneira, não bastava aos futuros professores fazerem apenas as atividades de ensino.

Assim, o licenciando sentiu necessidade de buscar novos referenciais teóricos que o auxiliassem a compreender, planejar e analisar as atividades experimentais a serem realizadas na escola de estágio. Essas necessidades surgiram, sobretudo, na segunda e terceira etapas do desenvolvimento do PID, nas quais o estagiário teve que refletir sobre uma situação-problema, fazer estudos teóricos e elaborar um plano de ensino e pesquisa. No caso analisado, na segunda etapa, o licenciando, a partir dos estudos realizados, formulou um problema de ensino-investigativo que articulava a experimentação por investigação, ensino de física moderna e aprendizagem significativa, explícito no portfólio do PID: "Quais elementos a experimentação por investigação no ensino de Física Moderna contribuem para a aprendizagem significativa do aluno sobre o tema dualidade (onda-partícula)?" [Portfólio PID].

O núcleo do problema investigativo formulado pelo licenciando contém o motivo que o impeliu a planejar sua atividade de ensino: a aprendizagem significativa dos estudantes. Esse motivo/objetivo nos diz que há uma nova necessidade 
geradora de um novo motivo, dessa vez coincidente com a atividade se formar para a futura docência. Esse motivo guarda ainda a importante relação com o objetivo da docência em Física, o de garantir a apropriação de conhecimentos científicos pelos estudantes. A experimentação passa a ser assumida pelo licenciando como uma ferramenta mediadora do processo de investigação no EF e de sua formação. Contudo, o fato de não ter conhecimentos suficientes sobre a experimentação Ihe impedia de realizar a atividade de ensino e resolver o problema de investigação, fazendo com que sentisse a necessidade desses conhecimentos, impulsionando ao estudo acerca dessa ferramenta metodológica específica do EF. Isto é, esse processo ocorreu devido a uma contradição secundária entre dois elementos do sistema de atividade: ferramentas e signos (experimentação), e objeto (aprendizagem dos alunos).

Dessa maneira, a necessidade de se apropriar de mais conhecimentos sobre as atividades experimentais se originou tanto nas leituras e discussões teóricas promovidas nas aulas de MEF como nas dificuldades geradas no desenvolvimento do PID. Ou seja, surgiu de uma limitação em seus conhecimentos e ações que o impediam de realizar a atividade em que estava mobilizado.

O licenciando, que antes desempenhava suas ações apenas para obter um diploma, começou a se envolver nas ações propostas pela disciplina; a alterar seu motivo, antes em caráter de apenas estímulo, para motivo gerador de sentido, uma vez que começou a assumir as dificuldades e a buscar superá-las.

Tal processo, que o levou a buscar novos referenciais, não surgiu de modo espontâneo, mas foi pari passu às possíveis necessidades formativas emergidas no processo de planejamento do seu projeto de investigação. Para que isso ocorresse, foram essenciais não só seus estudos pessoais e suas experiências vivenciadas no estágio, mas também as leituras e discussões coletivas dos textos teóricos realizadas nas disciplinas de MEF. Em seu portfólio, o licenciando afirma que, durante as aulas e com as reflexões teóricas realizadas, a questão que se destacou foi:

Como fazer com que os alunos aprendam física de maneira significativa? Através de leituras e análises da literatura acadêmica sobre o tema e as discussões coletivas feitas em sala, concluímos que um fator que contribui para a aprendizagem significativa dos alunos é a experimentação em física. [Relatório do PID].

Percebe-se, então, que a atividade da disciplina de MEF produziu modificações no licenciando, possibilitando leituras e discussões coletivas dos textos teóricos. Essa contradição quaternária, como as demais contradições que emergiram no processo de desenvolvimento do estágio supervisionado, descritas anteriormente, estão representadas na Figura 4.

Essa representação nos ajuda a visualizar como diferentes fatores, tanto internos à atividade central do estágio supervisionado, como externos, advindos de sistemas de atividades próximos à atividade central, possibilitaram o surgimento de contradições que impulsionaram a mudança dos motivos do licenciando ao realizar o estágio supervisionado.

Provavelmente, caso tivesse mantido apenas o motivo-estímulo de ter o menor trabalho possível na disciplina, representado pelas contradições de nível primário, poucas mudanças ocorreriam em seus sentidos sobre a aprendizagem dos alunos e a experimentação no EF. Contudo, ao mobilizar o licenciando para que fizesse leituras teóricas, discussões coletivas nas aulas e elaborasse um problema de ensino e pesquisa 
que Ihe é próprio, as atividades realizadas no estágio supervisionado deslocaram seu motivo. Esse, inicialmente, constituído como um motivo-estímulo passou, ao longo do processo, a se constituir um motivo gerador de sentido que, por sua vez, coincidiam com os objetivos formativos almejados pelo estágio supervisionado realizado com o PID. Dessa maneira, o estágio desse sujeito, que, no início se configurava como uma ação da sua atividade de certificação acadêmica, passou a atuar como uma "força motivante independente", tornando-se uma "variedade especial de atividade" (LEONTIEV, 1980, p. $57)$.

Figura 4 - Contradições que emergiram do sistema estágio supervisionado

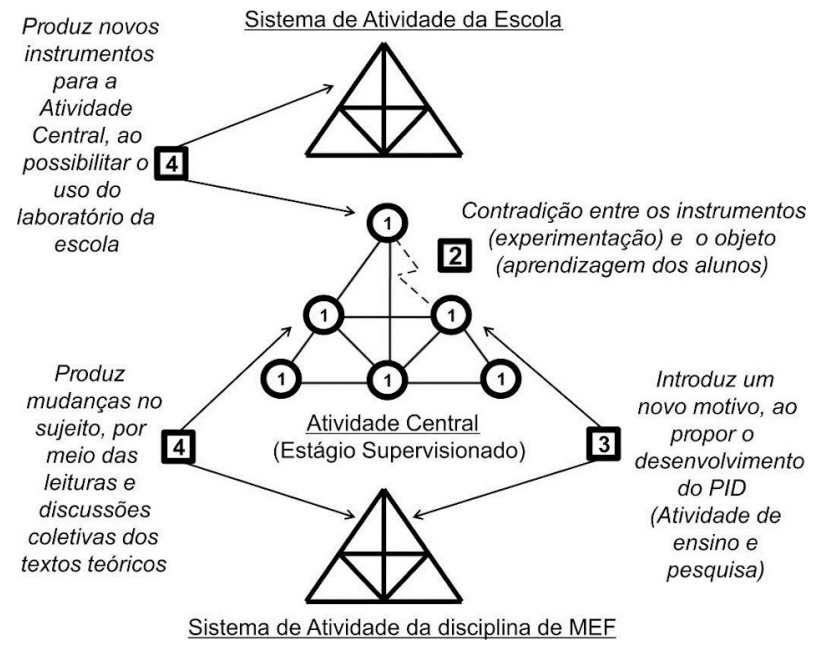

Fonte: elaborado pelos autores.

Dessa forma, o sujeito passou do plano da alienação para o plano da construção da atividade do estágio supervisionado na perspectiva da práxis, importante para o seu desenvolvimento como futuro professor. Ou seja, a atividade de estágio se configurou como uma unidade dialética entre teoria e prática (SAVIANI, 2009). Essa unidade representa "[...] a atividade livre, universal, criativa e autocriativa, por meio da qual o homem cria (faz, produz), e transforma (conforma) seu mundo humano e histórico e a si mesmo" (BOTTOMORE, 1997, p. 292). Assim sendo, podemos supor que a mudança no motivo gerou a mudança no conteúdo de seus sentidos sobre a aprendizagem dos alunos e a experimentação no EF.

Os sentidos anteriores à MEF e os novos sentidos sobre a aprendizagem dos alunos e a experimentação no EF podem ser constatados nos trechos apresentados no Quadro 1.

Os trechos apresentados no Quadro 1 evidenciam que houve a alteração dos sentidos do licenciando sobre elementos importantes da atividade do professor de Física. Ele passou a diferenciar a aprendizagem significativa de outros tipos de aprendizagens. Para ele, a aprendizagem significativa deve ser buscada pelo professor, de modo a não só transmitir os conteúdos curriculares, mas promover um entendimento mais amplo da Física, por meio da alfabetização científica dos alunos, e permitindo que o aluno relacione o que aprendeu com o seu cotidiano. Para isso, segundo o licenciando, embora haja diferentes abordagens experimentais que possam favorecer a aprendizagem significativa dos alunos, as atividades experimentais investigativas têm maior potencial para alcançar esse objetivo, pois motivam os estudantes e apresentam material potencialmente significativo. 
Quadro 1 - Sentidos sobre a aprendizagem dos alunos e a experimentação no Ensino de Física

\begin{tabular}{|c|c|}
\hline Sentidos & Trechos: entrevista e portfólio \\
\hline $\begin{array}{l}\quad \text { Sentidos anteriores à MEF } \\
\text { - Aprendizagem como recepção de } \\
\text { informações; } \\
\text { - Experimentação como forma de de- } \\
\text { monstrar e aplicar as teorias. }\end{array}$ & $\begin{array}{l}\text { Pra mim, aula era lousa, teorema, demonstração e exemplo. [Entrevista]. } \\
\text { A experiência que eu tinha com experimento era restrita aos laboratórios daqui } \\
\text { da graduação. [...] E que é muito diferente do que se faz no ensino médio, eu } \\
\text { acho. Até por uma questão de estrutura. [Entrevista]. }\end{array}$ \\
\hline $\begin{array}{l}\text { Novos sentidos } \\
\text { - Experimentação para a aprendiza- } \\
\text { gem dos meios de produção do co- } \\
\text { nhecimento físico e para a alfabeti- } \\
\text { zação científica dos alunos; } \\
\text { - Diferentes formas de atividades expe- } \\
\text { rimentais podem propiciar diferentes } \\
\text { aprendizagens aos alunos; } \\
\text { - As atividades experimentais investi- } \\
\text { gativas têm maior potencial de pro- } \\
\text { piciar a aprendizagem significativa } \\
\text { dos alunos. }\end{array}$ & 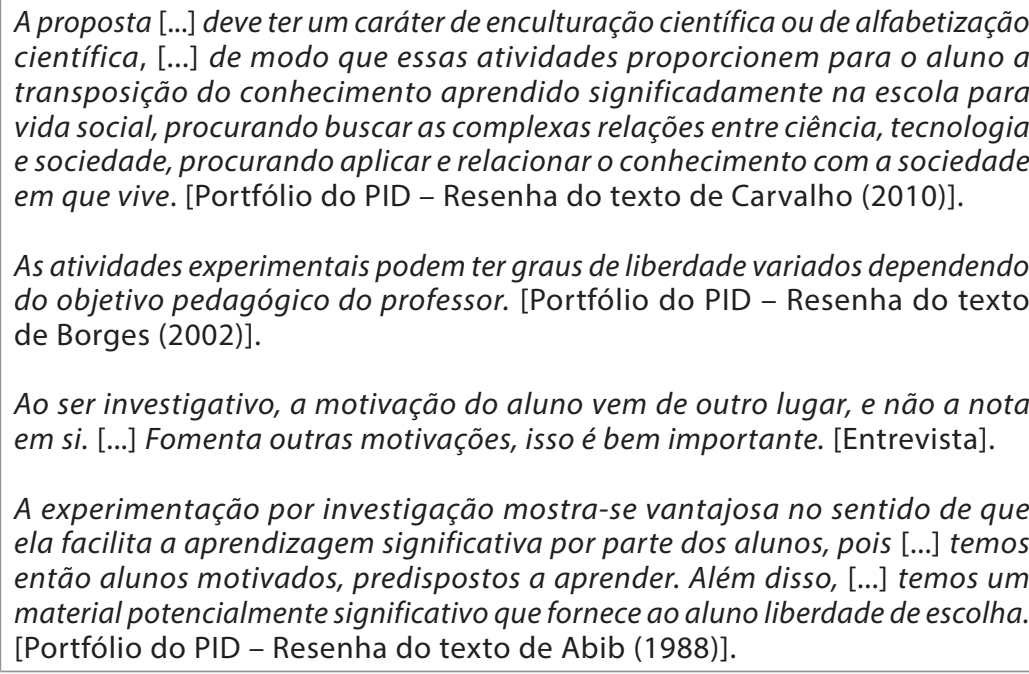 \\
\hline
\end{tabular}

Fonte: elaborado pelos autores.

Esses novos sentidos foram elaborados, não só por meio das vivências práticas do estágio supervisionado, mas, pelas articulações teórico-práticas, pois revelam uma apropriação teórica dos textos lidos e trabalhados nas discussões de grupo das aulas ocorridas nas MEF. Dessa forma, há indicativos de que as leituras teóricas e outras ações que possibilitaram as articulações teórico-práticas reveladoras da práxis e desenvolvidas na disciplina de MEF, influenciaram na produção pelo licenciando de novos sentidos sobre a atividade docente.

\section{Considerações Finais}

Neste artigo investigamos as transformações dos sentidos de um licenciando para realizar o estágio supervisionado acerca da aprendizagem dos alunos e da experimentação no Ensino de Física. Para tanto, buscamos conhecer seus motivos no início e no final da atividade de estágio.

Os resultados indicam que, ao iniciar o estágio supervisionado, o licenciando estava mobilizado apenas por motivos-estímulos, os quais não eram coincidentes com os objetivos formativos do estágio supervisionado das disciplinas de MEF, isto é, com a aprendizagem teórico-prática da atividade docente. Esses motivos desencadeavam sentidos, cujos conteúdos estavam limitados a obter os créditos necessários à certificação no curso de licenciatura em Física. Já os seus sentidos sobre o aprendizado dos alunos e a experimentação no EF eram limitados às experiências que ele teve como aluno no ensino básico e no ensino superior. Para ele, o aprendizado dos alunos ocorria por meio de um processo de transmissão de informações, por parte do professor, e recepção passiva pelo aluno. E seus sentidos sobre a experimentação no EF eram restritos às aulas de laboratórios de Física que participou durante a graduação, ou seja, com 
experimentos de verificação, muitas vezes com roteiros fechados. Entretanto, com o desenvolvimento do estágio supervisionado, seus motivos e sentidos foram se alterando.

Ele passou a ser mobilizado por motivos geradores de sentido e seus sentidos sobre a aprendizagem dos alunos e a experimentação no EF foram ampliados. A mobilização do licenciando por motivos geradores de sentidos o levou a realizar ações para além das exigidas na disciplina, o que se opunha ao motivo-estímulo inicial de realizar o estágio supervisionado com menor trabalho possível. Isso lhe permitiu se apropriar de novos referenciais teóricos sobre o EF, possibilitando-lhe produzir novos sentidos sobre atividades experimentais e aprendizagem dos alunos.

Desse modo, o estágio supervisionado que antes era apenas uma ação necessária à sua atividade de certificação acadêmica do licenciando, passou a se configurar como uma atividade. Esse processo ocorre ao longo do estágio supervisionado e não a priori, denotando a importância das ações realizadas na MEF. Inicialmente, as contradições (primária e terciária), as quais surgiram no início do processo de desenvolvimento do estágio, não haviam promovido o surgimento de motivos geradores de sentidos. Com a mediação da docente da universidade, a qual possibilitou o surgimento de contradições terciárias e secundárias, houve a transformação do sistema de atividade do sujeito. Para isso, foram importantes: as ações de introdução de leituras teóricas com conteúdos de cunho metodológico e científico, próprios das áreas de Física e do ensino dessa disciplina; as discussões coletivas nas aulas de MEF; as atividades que exigiam autonomia dos licenciandos, incentivando-os a desenvolver a criatividade; e, sobretudo, a proposição do estágio com pesquisa, por meio do desenvolvimento do PID, possibilitando a mobilização do sujeito a partir dos seus próprios motivos e interesses. Dessa maneira, pelo seu potencial de articulação teórico-prática, o estágio supervisionado com pesquisa, organizado com o PID, pode mobilizar os sujeitos envolvidos em uma atividade, por meio de motivos geradores de sentido, favorecendo a produção de novos sentidos sobre a docência.

\section{Agradecimentos}

Este trabalho foi realizado com apoio da Coordenação de Aperfeiçoamento de Pessoal de Nível Superior (CAPES), Código de Financiamento 001.

\section{Referências}

ABIB, M. L. V. S. Uma abordagem piagetiana para o ensino de flutuação dos corpos. São Paulo: Editora da Faculdade de Educação da USP, 1988. (Textos Pesquisa Para o Ensino de Ciências, 2).

AZEVEDO, M. N. Mediação discursiva em aulas de ciências, motivos e sentidos no desenvolvimento profissional docente. 2013. 272 f. Tese (Doutorado em Educação) - Faculdade de Educação, Universidade de São Paulo, São Paulo, 2013.

AZEVEDO, M. N.; ABIB, M. L. V. S.; TESTONI, L. A. Atividades investigativas de ensino: mediação entre ensino, aprendizagem e formação docente em ciências. Ciência \& Educação, Bauru, v. 24, n. 2, p. 319-335, 2018. DOI: https://doi.org/10.1590/1516-731320180020005.

BASTOS, F.; NARDI, R. Formação de professores: aspectos concernentes à relação teoria-prática. In: BASTOS, F.; NARDI, R. Formação de professores para o ensino de ciências naturais e matemática: aproximando teoria e prática. São Paulo: Escrituras, 2018. p. 19-46. 
BORGES, A. T. Novos rumos para o laboratório escolar de ciências. Caderno Brasileiro de Ensino de Física, Florianópolis, v. 19, n. 3, p. 9-31, 2002. Disponível em: https://periodicos.ufsc.br/index. php/fisica/article/view/6607. Acesso em: 25 jan. 2021.

BOTTOMORE, T. Dicionário do pensamento marxista. Rio de Janeiro: Jorge Zahar, 1997.

CARVALHO, A. M. P. As práticas experimentais no ensino de física. In: CARVALHO, A. M. P (org.). O ensino de física. São Paulo: Cengage Learning, 2010. p. 53-77.

ENGESTRÖM, Y. Expansive learning at work: toward an activity theoretical reconceptualization. Journal of Education and Work, Abingdon, v. 14, n. 1, p. 133-156, 2001.

ENGESTRÖM, Y. Learning by expanding: an activity-theoretical approach to developmental research. Helsinki: Orienta-Konsultit, 1987.

ENGESTRÖM, Y.; SANNINO, A. Studies of expansive learning: foundations, findings and future challenges. Educational Research Review, Amsterdam, v. 5, n. 1, p. 1-24, 2010. DOI: https://doi. org/10.1016/j.edurev.2009.12.002.

GIROUX, H. Os professores como intelectuais: rumo a uma pedagogia crítica da aprendizagem. Porto Alegre: Artmed, 1997.

GONZÁLEZ-REY, F. Pesquisa qualitativa e subjetividade: os processos de construção da informação. São Paulo: Cengage Learning, 2015.

LEONTIEV, A. N. Atividade e consciência. In: MAGALHÃES-VILHENA, V. (org.). Práxis: a categoria materialista de prática social. Lisboa: Livros Horizonte, 1980. p. 49-77.

LEONTIEV, A. N. Actividad, conciencia e personalidad. Buenos Aires: Cartago, 1984.

LEONTIEV, A. N. O desenvolvimento do psiquismo. 2. ed. São Paulo: Centauro, 2004.

LEONTIEV, A. N. Uma contribuição à teoria do desenvolvimento da psique infantil. In: VIGOTSKI, L. S.; LURIA, A. R.; LEONTIEV, A. N. Linguagem, desenvolvimento e aprendizagem. 11. ed. São Paulo: Ícone, 2010. p. 59-83.

LIBÂNEO, J. C. Antinomias na formação de professores e a busca de integração entre o conhecimento pedagógico- didático e o conhecimento disciplinar. In: MARIN, A. J.; PIMENTA, S. G. (org.). Didática: teoria e pesquisa. São Paulo: Junqueira \& Marin, 2018. p. 39-65.

LIMA, M. S. L.; PIMENTA, S. G. Estágio e docência: diferentes concepções. Poíesis Pedagógica, Catalão, v. 3, n. 3-4, p. 5-24, 2006. DOI: https://doi.org/10.5216/rpp.v3i3e4.10542.

MARX, K. O capital: volume 1. São Paulo: Nova Cultural, 1985.

PIMENTA; S. G.; LIMA, M. S. L. Estágio e docência. 8. ed. São Paulo: Cortez, 2017.

SAVIANI, D. Sistema de educação: subsídios para a conferência nacional de educação. [2009]. Disponível em: https://cutt.ly/hksMrME. Acesso em: 25 jan. 2021.

SILVA, J. C. Educação e alienação em Marx: contribuições teórico metodológicas para pensar a história da educação. Revista HISTEDBR, Campinas, n. 19, p. 101-110, set. 2005.

TARDIF, M.; RAYMOND, D. Saberes, tempo e aprendizagem do trabalho no magistério. Educação \& Sociedade, Campinas, ano 21, n. 73, p. 209-244, 2000.

VIGOTSKI, L. S. A formação social da mente: o desenvolvimento dos processos psicológicos superiores. 7. ed. São Paulo: Martins Fontes, 2010.

ZEICHNER, K. M.; DINIZ-PEREIRA, J. E. Pesquisa dos educadores e formação docente voltada para a transformação social. São Paulo. Cadernos de Pesquisa, São Paulo, v. 35, n. 125, p. 63-80, 2005. 